\title{
Humean compatibilism
}

DOI:

$10.1093 / \mathrm{mind} / 111.442 .201$

\section{Document Version}

Accepted author manuscript

Link to publication record in Manchester Research Explorer

\section{Citation for published version (APA):}

Beebee, H., \& Mele, A. (2002). Humean compatibilism. Mind, 111(442), 201-223.

https://doi.org/10.1093/mind/111.442.201

\section{Published in:}

Mind

\section{Citing this paper}

Please note that where the full-text provided on Manchester Research Explorer is the Author Accepted Manuscript or Proof version this may differ from the final Published version. If citing, it is advised that you check and use the publisher's definitive version.

\section{General rights}

Copyright and moral rights for the publications made accessible in the Research Explorer are retained by the authors and/or other copyright owners and it is a condition of accessing publications that users recognise and abide by the legal requirements associated with these rights.

\section{Takedown policy}

If you believe that this document breaches copyright please refer to the University of Manchester's Takedown Procedures [http://man.ac.uk/04Y6Bo] or contact uml.scholarlycommunications@manchester.ac.uk providing relevant details, so we can investigate your claim.

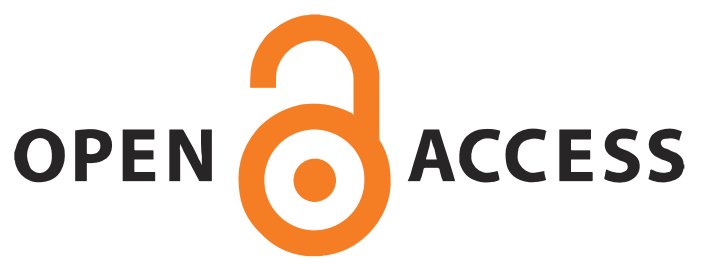




\section{Pre-publication version: DO NOT CITE}

\section{HUMEAN COMPATIBILISM}

Helen Beebee \&Alfred R. Mele, Mind, 111 (2-2): 201-23.

The physical world recently came to an end. The cosmic scribe, Sam, had diligently recorded everything that had happened, and the cosmic pattern expert, Pat, on the basis of a thorough examination of Sam's data, got to work on figuring out which (non-trivial) true universal generalisations held. She noticed that a description of very early conditions of the world-conditions Sam recorded when things began to settle down after the Big Bang-plus a subset of her list of regularities were sufficient to entail all subsequent items on Sam's list. Being a Humean about laws, Pat concluded that she had thereby discovered what the laws of the physical world were. She also concluded that the world was deterministic. (She was most pleased with this discovery, being a naturally neat and tidy person.)

Because she was a Humean about laws, Pat went on to reflect that the world need not have turned out that way. In her view, Sam's list might have started out just as it did, but then begun to diverge from the actual list after a day, a week, or a million years in such a way as eventually to show the world to be non-deterministicor to have a different collection of deterministic laws. (Pat had not been kicking her heels during the long wait for the end of the world: she had been busy practising her art. She would often get Sam to make up hypothetical lists and see what cosmic patterns she could discern in them; more often than not, the results were displeasingly untidy.) 
Along with everything else, Sam had recorded disputes over the compatibility of determinism and free will. These disputes had piqued Pat's interest, and, having recently discovered that the world was in fact deterministic, she fell to wondering whether any of the human beings there had had free will. Pat's philosophical reflections produced some positive results. In particular, her Humean conception of laws led her to conclude that agents in the world she had been investigating had frequently had the ability to do otherwise than what they actually did, even though it turned out that the world was deterministic. In this paper, we show that it was reasonable for Pat to draw that conclusion, given her Humean conception of laws, but we also argue that her 'Humean compatibilism' faces an important problem. Our aim is to situate Humean compatibilism in the debate among libertarians, traditional compatibilists, and semicompatibilists about free will. Some striking similarities will emerge between Humean compatibilism and libertarianism; they are noteworthy in their own right. Furthermore, in the absence of a compelling argument for a nonHumean view of laws of nature, the bearing of a Humean conception of laws on the issue of free will merits more attention than it has received.

Following a brief discussion of Humeanism about laws in $\S 1$, we argue in $\S \S 2$ and 3 that a Humean about laws can hold that there is a sense in which the laws of nature are 'up to us' and hence that the leading style of argument for incompatibilism-the 'consequence argument'-has a false premise. We show, finally, that it is not all plain sailing for Humean compatibilists. Standard libertarians face a problem about luck, and in $\S 4$ we show that Humean compatibilists face a strikingly similar problem.

\section{Humeanism about laws}


Humeanism about laws stems primarily from a suspicion of irreducible necessary connections. Some Humeans have epistemic concerns about necessary connections: following Hume, they hold that necessary connections cannot be observed, and hence that a belief in their existence is inconsistent with an empiricist epistemology. Some Humeans have what might be called ontological concerns about necessary connections: they find the very idea of a necessary connection to be so peculiar that they do not wish to postulate such dubious entities (or, more strongly, they find the notion of a necessary connection simply unintelligible).

Since we are interested in what might have gone through Pat's mind when she wondered whether any human beings in the deterministic world at issue had free will, and since Pat is a Humean, we will simply take Humeanism for granted in this paper. It is therefore not our business here to try to defend or motivate Humeanism about laws. (For recent defences of Humeanism, see Loewer 1996 and Beebee 2000.) But we still need to say something about what positive view about laws a Humean denier of necessary connections might hold.

As a first pass, following David Armstrong (1983, pp. 11-12), let us define the 'Naïve Regularity Theory' thus: the laws of nature are those 'Humean uniformities' that make statements of law true, where a statement of law is a true, contingent, universally quantified sentence containing only non-local empirical predicates and the machinery of first order predicate logic. Humean uniformities are simply, as Armstrong puts it, 'nothing but regularities in the behaviour of things' (1983, p. 11).

As Armstrong goes to great lengths to show, the Naive Regularity Theory is an utterly untenable position (1983, chs. 2-4). One reason is that it counts as laws all sorts of regularities that are not laws-for example accidental regularities, single-case uniformities, and uniformities with non-existent subjects. A Humean about laws 
therefore needs to have a more sophisticated analysis of lawhood that rules out those regularities that are manifestly not laws. The most plausible such account currently on offer is the Ramsey-Lewis View (after Ramsey 1978 and Lewis 1973, pp. 73-75). ${ }^{1}$ According to this view, a law of nature is a contingent generalization that 'appears as a theorem (or axiom) in each of the true deductive systems that achieves a best combination of simplicity and strength' (Lewis 1973, p. 73).

For the purposes of this paper, we do not need to defend or even endorse any particular Humean view of laws, since we are interested only in how a broadly Humean conception of laws affects the debate about free will. We therefore simply assume that some Humean view or other is correct-in other words, some view according to which laws of nature are merely some subset of the Humean uniformities that in fact hold in the world that was the object of Pat's attention (henceforth, 'world $\left.W_{i}{ }^{\prime}\right)$. We remain neutral about how one might specify which of those Humean uniformities are the laws of nature.

What is important about a Humean view of laws in the context of a discussion about free will is that the facts about the world that determine what the laws are are facts about the whole duration of the world, including (in worlds that have not yet ended) facts about the future. Imagine Sam busily composing her list as the history of $W_{i}$ unfolds. On a Humean conception of laws, while the history of the world is still unfolding, nothing on Sam's list guarantees that the laws of nature are such-and-such rather than so-and-so. Pat might spot the extraordinary orderliness of the world as it has unfolded so far and assume that events are going to continue to unfold in the same orderly way; she might even take herself to have excellent reason to think this, and hence take herself to know what the laws are, since she is already in a position to

\footnotetext{
${ }^{1}$ The view is sometimes called the Mill-Ramsey-Lewis view (see Mill 1875, Bk.3, Ch.5).
} 
establish conclusively that certain regularities have held up until now. (Pat's view on this matter depends, of course, on how moved she is by the problem of induction.) But there is no feature of the history of the unfinished world that guarantees that events will continue to unfold in a way consistent with her current best guess at what the laws are. ${ }^{2}$

If it seems uncontroversial that this is the position in which Pat finds herself, it is worth considering how Pat's and Sam's respective jobs would differ under a nonHumean conception of laws of nature. According to Armstrong, for example, laws are constituted by a contingent relation of necessitation between universals: it is a law that all $F \mathrm{~s}$ are $G$ s if and only if the contingent necessitation relation $N$ holds between the universals $F$ and $G$. (Armstrong writes this ' $N(F, G)^{\prime}$ '.) $N$ is contingent in the sense that it is a contingent matter which universals $N$ relates-or indeed whether $N$ is instantiated at all. But, given that, say, $N$ in fact relates $F$ and $G$, an object's being $F$ necessitates its being $G: N(F, G)$ entails that all actual $F$ s are $G \mathrm{~s}^{3}$ So, assuming that $W_{i}$ in fact has laws of nature-assuming, that is, that the regularities are not just cosmic coincidences-the fact that $W_{i}$ contains laws of nature means that when Sam records what happens, one of the things she records is the instantiation of $N$. Once Pat notices that $N$ has been instantiated (say, between universals $F$ and $G$ ), she can infer directly, without having to wait and see how events unfold later, that it is a law that all $F$ s are Gs. (This is not to say that Armstrong's view trivially avoids the problem of induction. It might be that, unlike Sam, we are able to make judgements about

\footnotetext{
2 This point, and its connection with standard arguments for incompatibilism, is also made by Vihvelin 1990, pp. 378-9.

${ }^{3}$ See for instance Armstrong 1983, pp. 85-93. In fact, Armstrong later modifies this claim, so that $N(F$, $G$ ) entails only that all uninterfered with $F s$ are $G$ s (see his 1983, pp. 147-150). This modification complicates matters, but not in a way that is relevant to our central point about the ontological ingredients of laws.
} 
whether and in what circumstances $N$ is instantiated only on the basis of observed regularities.)

In other words-assuming determinism-on a necessitarian view of laws, facts about properties and relations that are instantiated in the world before $t$ are sufficient to guarantee that the world will pan out a certain way after $t$, since if there is a necessary connection $N$ between, say, $F$ and $G$, the obtaining of that necessary connection entails that all $F$ s will continue to be $G$ s. On a Humean view, by contrast, facts about which properties and relations have already been instantiated do not entail anything like this about how the world will pan out. If the world is the way Armstrong says it is, the ontological ingredients of laws of nature are already present; if the world is the way Humeans say it is, some of the ontological ingredients of laws of nature-namely, future regularities-have yet to fall into place.

Given this much, one might wonder whether Humeanism itself really is compatible with determinism: if laws are partly determined by future regularities, one might wonder whether facts about future regularities really are determined by past facts plus the laws. Indeed, it seems that the 'determination' runs in the opposite direction: facts about future regularities determine the laws.

In a sense, this line of thought is correct. On a Humean conception of laws, future regularities do (partly) determine what the laws are and not the other way around, where 'determine' means 'provide the ontological grounds for', or 'make true', or some such. However, this sense of 'determine' is not the sense at work in the thesis of determinism. Determinism is a thesis about entailment relations between, on the one hand, statements of law and statements about the state of the world at a given time and, on the other, statements about the state of the world at any other time. In the forward direction, it is the thesis that past facts plus statements of the laws entail all 
future facts. If Humeanism is true, it is still true of Sam and Pat's world that a comprehensive statement of the laws and very early conditions entails all the facts that obtain until the end of the world. But that is because the laws themselves are, in large part, facts about what happens long after the world has got going. It is no part of the thesis of determinism that there is a metaphysical determination (whatever that means) of future facts by laws plus past facts.

\section{Humean laws and compatibilism}

Compatibilism is the thesis that free will and moral responsibility are compatible with determinism. Incompatibilism is the thesis that determinism is incompatible with both of these things. Some incompatibilists believe that at least some human beings are free and morally responsible agents. They are libertarians, libertarianism being the conjunction of incompatibilism and the belief just reported about freedom and moral responsibility. Traditional compatibilists hold that determinism is compatible with the ability to have acted otherwise than one did and that freedom and moral responsibility require that ability (see e.g. Moore 1912, Ch.6 and Ayer 1954, Ch.12). Traditional incompatibilists contend that determinism is incompatible with freedom and moral responsibility because it is incompatible with the ability just identified. We call this ability 'dual ability', on the assumption that there is a legitimate sense of 'able' in which any agent was able to act as she in fact acted. Not all compatibilists are traditional. John Fischer, for example, holds that compatibilism (as we defined it) is true even if, as incompatibilists claim, determinism is incompatible with dual ability (1994). Obviously, Fischer, unlike his incompatibilist opponents, holds that free will and moral responsibility do not require dual ability. He labels his view 
'semicompatibilism' (p. 180). We have something to say about semicompatibilism later.

Some background from the incompatibilist camp is in order in introducing a compatibilist position that appeals to a Humean conception of laws of nature. The most influential argument in circulation for incompatibilism is the 'consequence argument'. Here is a short version offered by Peter van Inwagen:

If determinism is true, then our acts are the consequences of the laws of nature and events in the remote past. But it is not up to us what went on before we were born, and neither is it up to us what the laws of nature are. Therefore the consequences of these things (including our present acts) are not up to us. (1983, p. 16)

Add the premise that any act performed by an agent that was not up to the agent is not a free act and is not one for which the agent is morally responsible. The conclusion is incompatibilism.

In this section, we explain that a Humean about laws need not accept this argument's third premise, that it is not up to us what the laws of nature are. Similarly for the corresponding premise, 'NL', in a modal version of the consequence argument that has received a lot of attention (van Inwagen 1983, pp. 93-105). Here, 'L' is an abbreviation for a proposition expressing the laws of nature, and ' $\mathrm{N}$ ' is an operator. ' $\mathrm{N} p$ ' is read as the conjunction of $p$ and 'no one has, or ever had, any choice about whether' $p$ (p. 93). The quoted expression may be read as an attempt to capture the idea that no one has or ever had the power to render $p$ false. The premise, then, expresses the laws of nature (of a world)-a certain collection of propositions-and 
asserts that no one ever had the power to falsify any of these propositions, that none of these propositions is such that its truth was ever, to any extent, up to anyone. $\mathrm{N}$ may be labelled the 'no choice' or 'not up to anyone' operator. ${ }^{4}$

Van Inwagen, then, has as a premise in his arguments for incompatibilism the claim that it is not 'up to us' what the laws of nature are-or, equivalently, that no one has the power to render laws of nature false-and it is this premise, on a pertinent reading, that a Humean about laws can deny. In this section we explain that a Humean about laws can hold that there is a sense in which laws of nature are 'up to us' (cf. Swartz 1985, pp. 126-27, 135).

We assume, with van Inwagen, that laws of nature impose limits on our abilities if and only if they are not 'up to us'. We also hold that ordinary future facts themselves do not impose limits on our abilities. Thus, we, like van Inwagen, reject the following general claim: 'If $\mathrm{P}$ is a true proposition, then no one can render $\mathrm{P}$ false' (1983, p. 62). Should Humeans agree with van Inwagen that laws of nature 'impose limits on our abilities' (p. 62)?

Consider Fred, who is undecided at $t$ whether or not to have toast for breakfast tomorrow morning, and suppose that in fact Fred will have toast for breakfast then. It is logically impossible that this fact obtain and that Fred skip breakfast tomorrow. But this logical impossibility does not impose any limit on Fred's ability to skip breakfast; and it does not entail that it is not up to Fred whether or not he skips breakfast, or that he cannot do otherwise than have toast for breakfast tomorrow. Fred will not do otherwise, but that does not entail that he cannot do otherwise, any more than the fact

\footnotetext{
${ }^{4}$ Van Inwagen distinguishes between a de dicto and a de re reading of the claim that no one can render a law of nature false (p. 63). His claim, as he says, is not the 'trivial' de dicto claim that, necessarily, no laws of nature are rendered false by anyone. (After all, nothing is both a law and false.) Rather it is the de re claim, of each proposition that is a law of nature-e.g. the proposition that 'momentum is conserved', if that is a law of nature-that no one can (= has the power to) render it false.
} 
that Fred had toast for breakfast yesterday entails that he could not have done otherwise yesterday.

Now suppose both that Humeanism about laws is true and that past facts plus the laws of nature entail that Fred has toast for breakfast tomorrow. ${ }^{5}$ A Humean about laws need not hold that there is any relevant difference between this case and the previous case when it comes to the question whether Fred is able to do otherwise. To say that the laws are such that together with past facts they entail that Fred eats breakfast tomorrow is already to presuppose that Fred eats breakfast tomorrow; but this presupposition, as we explained, does not itself strip Fred of the ability to decide whether or not to skip breakfast and act accordingly. It may still be up to Fred whether or not he eats breakfast. On a Humean conception of laws, just as facts about the future do not deprive us of present dual ability, facts about what laws there are do not deprive us of such ability either, since the relevant feature of laws just is the fact that part of what laws describe is the future. Thus a Humean-unlike van Inwagen-can reject the general claim that 'if $\mathrm{P}$ is a law of nature, then no one can render $\mathrm{P}$ false' (1983, p. 63).

Another way to put the point runs as follows. When it is asked whether someone-Fred, say-could have done otherwise, one might attempt to answer that question by ascertaining whether there are any possible worlds in a particular class of possible worlds in which Fred does otherwise (in this case, skips breakfast). Which class of worlds is the appropriate class against which to assess whether or not Fred could have done otherwise in a sense that is relevant to the question of whether or not Fred is able to skip breakfast? We agree with van Inwagen that the class should

\footnotetext{
${ }^{5}$ Obviously, we do not include among 'past facts' the fact that Fred will have toast for breakfast tomorrow. That would make the entailment trivial. We forego the notoriously difficult project of providing an analysis of the pertinent notion of 'past fact' or 'fact about the past'. For instructive discussion, see Fischer 1994, Ch.6.
} 
include only worlds that have the same past as the actual world (on the assumption that Fred is an actual human being). Van Inwagen holds additionally that it should include only worlds that have the same laws as our own. Given this further assumption (plus determinism and the assumption that a test in terms of possible worlds is legitimate in the present connection), it obviously follows that Fred is not able to skip breakfast, since in all relevant worlds Fred has toast for breakfast.

From the Humean perspective that we have been articulating, this further assumption is simply unmotivated. Imagine that Fred is an inhabitant of the world that is the object of Pat's attention, $W_{i}$. While waiting for the world to end, Pat gets hold of Sam's list of what has happened up to $t$, the time at which Fred is thinking about tomorrow's breakfast. Pat may be well aware that if the regularities that have held so far continue to hold, Fred will in fact have toast for breakfast. But-being a Humeanshe is also firmly of the opinion that the world might, consistent with what has happened so far, pan out in many different ways: there are many possible worlds with exactly the same past as her world, and in some of them Fred decides to, and does, skip breakfast. As far as Pat can see, nothing in what has happened so far guarantees that her world will not be one of those worlds. From Pat's Humean perspective, it seems rather peculiar to claim that in order to judge whether Fred has the ability to skip breakfast she has to wait for the end of the world, figure out what the laws are, and then-retrospectively-make a call on Fred's current ability to skip breakfast.

Pat's Humean perspective, then, imposes a modus tollens on van Inwagen's quick argument quoted above-and, a fortiori, on the modal version of the consequence argument. Since, in his deterministic world, it is up to Fred whether or not he skips breakfast, and it is manifestly not up to Fred what went on in the distant past, it is up to Fred what the laws of nature are. We admit that this may sound 
peculiar to some readers, but to Pat's Humean ears it is merely a way of saying that laws do not have the kind of ontological clout that would enable them genuinely to impede exercises of free will.

According to the Humean view we have been assuming, there is no feature of the world that deprives Fred of the ability to skip breakfast tomorrow. However, we are not claiming that this is a consequence that all Humeans about laws should accept. For example, Humeanism about laws is consistent with fatalism. A Humean fatalist should accept premise 3 of the consequence argument (the premise that the laws of nature are not up to us), but only because she already holds that facts about the future (upon which the laws of nature depend) are not up to us. In what follows, we ignore such views: that is, we shall be assuming a Humean view of laws according to which neither the laws nor any other general feature of the world deprives Fred of the ability to skip breakfast.

Suppose that physical possibility and impossibility of dated events are to be defined in terms of laws of nature as follows: $x$ 's occurring at $t$ is physically possible in a world $W$ if and only if $x$ 's occurring at $t$ is consistent with the laws of nature in $W$ together with the state of world at all times prior to $t$; otherwise, $x$ 's occurring at $t$ is physically impossible in $W$. (Of course, if an event's occurrence is inconsistent with a law or laws alone, it is inconsistent with the combination of the law(s) and the past.) Now suppose that a Humean conception of laws of nature is correct. It can turn out that some agents are able to do things that it is physically impossible to do (cf. Swartz 1985, p. 127). It can turn out that the laws of nature are deterministic and that a true statement of the laws together with a true description of the state of the world a billion years ago entails that Fred will have toast for breakfast tomorrow morning. And, even so, it can be up to Fred whether he eats toast for breakfast and within his power, for 
example, to eat cake instead, or to skip breakfast in favour of a brisk hike. If he were to skip breakfast tomorrow or eat cake instead of toast, then the laws would not be what they in fact turned out to be.

The claim that Fred is able to do something that it is physically impossible to do has an odd ring. A Humean about laws who finds that ring intolerable can eke out an alternative conception of physical impossibility. However, in our opinion, if it is held firmly in mind that, on a Humean view, a world's laws are not written, as it were, until the world has come to an end, and that, on the account of physical impossibility at issue, determinations of what is physically (im)possible are made only from that final perspective, the bad sound goes away. As it turned out, Fred occupied a deterministic world with a particular collection of laws, but-even on the morning in question-it need not have turned out that way. Fred's world might have turned out to be indeterministic, or it might have had a different collection of deterministic laws that, together with a complete description of the state of the world a billion years earlier, entails that Fred eats cake rather than toast for breakfast.

Are we saying that Fred is free to break the laws? No. Necessarily, nothing is both a deterministic law of nature and broken. Our claim, rather, is that on a Humean conception of laws, Fred, who ate toast for breakfast in his deterministic world, was able to eat something else for breakfast instead, or nothing at all, and if he had done so, the laws would have been (a bit) different. Although Fred ate toast for breakfast, he could have done otherwise.

We used the image of the laws of nature not being written before the world's end. This is not to deny that statements of law are timelessly true; nor is it to deny that they are true at all times. We have not taken a stand on this issue. If statements of law are true in either of the ways just mentioned, the same may be so of the statement that 
Fred eats toast for breakfast on January 1, 2003. The truth of the latter statement does not stand in the way of Fred's being able to eat cake instead for breakfast on that future day. On a Humean view, the same is true of the laws of nature.

\section{A worry about Humeanism}

The tack we have taken may usefully be compared with David Lewis's tack in 'Are we Free to Break the Laws?' (1981). Lewis's aim in that paper is to show that determinism and freedom are compatible, and he attempts to do so by arguing that the ability to raise his hand, say-an ability Lewis claims to have-does not entail the ability to do things like run faster than the speed of light. More precisely, he argues that, while

(Weak Thesis) I am able to do something such that if I did it, a law would be broken

is true, it does not entail

(Strong Thesis) I am able to break a law, which, he claims, is false. ('A marvelous power indeed! Can you also bend spoons?' [1981, p. 292].)

Lewis's so-called 'local miracle compatibilism' (see e.g. Fischer 1994, p. 69) is so called because Lewis asserts, to use our current example, that if Fred had eaten cake for breakfast, 'a law would have been broken beforehand' (1981, p. 294). 'The course of events would have diverged from the actual course of events a little while before' Fred began eating cake, 'and at the point of divergence there would have been a law-breaking event-a divergence miracle'. ${ }^{6}$

\footnotetext{
${ }^{6}$ Moreover, Fred's cake eating 'was altogether absent from the actual course of events, so it cannot get underway until there is already some divergence' (ibid.). One might find this a bit misleading. From Pat's perspective at the end of the world, after the laws are written, if Fred had eaten cake for breakfast on the day at issue, a miracle would have occurred. However, from the perspective of the world in
} 
Now, Lewis does not say what he means by 'ability'; nor does he attempt to motivate the weak thesis above. He says:

there is a true historical proposition $H$ about the intrinsic state of the world long ago, and there is a true proposition $L$ specifying the laws of nature that govern our world, such that $H$ and $L$ jointly determine what I did. They jointly imply the proposition that I put my hand down. They jointly contradict the proposition that I raised my hand. Yet I was free; I was able to raise my hand. The way in which I was determined not to was not the sort of way that counts as inability. (pp. 291-92)

We agree with Lewis on this point (although we find the word 'govern' misleading) ${ }^{7}$ and with his claim that were Fred to have cake for breakfast, a law would be broken (and therefore would not be a law but 'at best ... an almost-law' [see n. 6]). Plainly, however, Lewis's claim that the way in which Fred was determined not to have cake for breakfast is 'not the sort of way that counts as inability' stands in need of support, since one might accept Lewis's analysis of counterfactuals and yet fail to be convinced that Fred does, in fact, have that ability; one might hold that the way in which Fred is determined to eat toast for breakfast is the sort of way that counts as or entails inability to do otherwise. What we have tried to do so far is to show why,

progress, there would be no miracle. Rather, Fred's eating cake for breakfast that day would be one of the facts to be accounted for by a web of contingent generalizations that appear as theorems (or axioms) 'in each of the true deductive systems that achieves a best combination of simplicity and strength' (Lewis 1973, p. 73). Although Lewis's putting things in terms of law breaking has been a source of some confusion, he is clear about what he means: 'That is not to say that anything would have been both a law and broken-that is a contradiction in terms if, as I suppose, any genuine law is at least an absolutely unbroken regularity. Rather, if $L$ had not been true, something that is in fact a law, and unbroken, would have been broken, and no law. It would at best have been an almost-law' (1981, p. 292).

${ }^{7}$ For defence of the view that on the Humean conception of laws, laws do not govern, see Beebee 2000 . 
given Humeanism about laws, it is reasonable to hold that the way in which Fred was determined not to eat cake was 'not the sort of way that counts as inability'.

What we have done so far, then, can be seen as an attempt to show how Humeanism about laws provides the missing support for the weak thesis. But what about the strong thesis? Here we part company with Lewis. Lewis is implicitly claiming that while he is able to raise his hand, he is not able, in the very same sense of 'able' at work in the weak thesis, to raise it faster than light. ${ }^{8}$ By contrast, one might worry that the Humean view outlined above has as a consequence not just that Fred is able to eat cake for breakfast tomorrow insofar as his doing so is consistent with his world's past (and the laws of logic), but also that he is able, in just the same sense, to move his arm faster than light, and to leap over Manchester Town Hall in a single bound.

This is a legitimate worry to have, because the Humean view does indeed have those consequences. The upshot of this is that the motivation we have provided for Lewis's weak thesis simultaneously undermines his denial of the strong thesis. This leaves the local miracle compatibilist in a tricky position. We have offered her a broad philosophical position-Humeanism about laws-that supports the weak thesis. But that support undermines the second claim of local miracle compatibilism: the claim that deterministic agents never have strong abilities, for example, the ability to move one's hand faster than light.

The problems that beset local miracle compatibilists are not our central concern, which is to show that a Humean view of laws can provide the starting point for a version of compatibilism that neatly side-steps the consequence argument. What

\footnotetext{
${ }^{8}$ Similarly, Norman Swartz maintains that whereas 'many physical laws derive their truth from our choosing and doing certain things', others 'seem to be quite outside [our] sphere of control' (1985, p. 126). But he does not attempt to show that his second claim is consistent with the Humean view that he takes to motivate the first claim.
} 
we have shown so far is that the ability to do otherwise is compatible with determinism, where the ability to do otherwise is determined solely by past facts, and that this sense of 'ability' is, from a Humean perspective, a legitimate one, since from that perspective there is a sense in which our abilities are not constrained by the laws of nature. We thus have a problem of our own to contend with, which is the worry that the Humean view we have been articulating has the absurd consequence that we are able to jump over large buildings in a single bound. One might be inclined to think that any view with such a consequence cannot possibly be true, and thus that what we have really done is found a reductio of Humeanism about laws lurking in a rather unexpected place.

We accept the consequence of Humeanism about laws, but we deny that this constitutes a good reason to reject the view. Our argument is as follows. The existence of the legitimate (by Humean lights) sense of ability already identified does not entail that there are no other legitimate senses of 'ability', consistent with Humeanism, according to which Fred is able to eat cake but unable to raise his hand faster than the speed of light. We will suggest one such sense of 'ability' below. Our response to the question, 'so does Humeanism about laws entail that I am able to clear the Eiffel tower in one bound?' is thus, 'it all depends which kind of ability you have in mind, and it is not bad news that Humeanism entails the kind of ability to do these things that it entails'.

Given the metaphysical openness entailed by Humeanism about laws, there is a possibility that Fred raises his hand faster than the speed of light. This is not a 'physical possibility', in the sense we defined in $\S 2$. Call it a 'metaphysical possibility', and call the ability that Fred has to raise his hand faster than the speed of light just in virtue of the metaphysical possibility of his raising his hand that fast a 
'metaphysical ability'. To insist that any theory that countenances this metaphysical possibility and this metaphysical ability is an unacceptable theory is to insist that Humeanism about laws is false. Now, as we said, our concern is not to show that a Humean view of laws is true but to situate Humean compatibilism in the current debate about free-will. Even so, we do not want to leave readers thinking that a Humean cannot distinguish between the metaphysical ability to raise one's hand faster than the speed of light (or the metaphysical ability to eat cake for breakfast) and an ability to eat cake for breakfast that requires more than just a metaphysical ability to do this. Humeans are committed to the former kind of ability, but this is not to say that they can have no place for the latter, more demanding kind of ability, as we will explain.

Consider Rocky and Emmy, two amateur inventors who compete with each other to build a miniature rocket that can clear Manchester Town Hall. An independent judge is called in to decide whose rocket is best, and the judge, having thoroughly examined the internal workings of both rockets, judges that Rocky's rocket can, and Emmy's cannot, clear the Town Hall. In fact, just after the judge's decision, both rockets are accidentally destroyed, so that the decision is never tested. This lack of evidence obviously does not itself render the judgement false. So in what sense can Rocky's rocket, but not Emmy's, clear the Town Hall?

There are various senses in which we might try to cash out the idea that Rocky's rocket can, and Emmy's cannot, clear the Town Hall. There is a very restrictive sense of 'can' according to which, assuming determinism, neither rocket can clear the Town Hall. The laws plus the past facts entail that neither rocket will ever be launched, and therefore that neither rocket will ever clear the Town Hall. Hence, in the sense of 'can' that holds the laws and the past fixed, neither rocket can 
clear the Town Hall. There is also a very inclusive sense of 'can' according to which both rockets can clear the Town Hall. This is the sense of 'can' that we have been describing, one that holds the past fixed, but not the laws.

Neither of these senses of 'can' legitimises the (plausible) thought that Rocky's rocket can, and Emmy's cannot, clear the Town Hall. But there is another sense of 'can' that does legitimise the distinction, a dispositional sense. Rocky's rocket, unlike Emmy's, is such that were it to be launched in the vicinity of the Town Hall, it would get high enough to clear the roof.

Now consider the contrast between Fred's ability to raise his arm and his ability to move his arm faster than the speed of light. One way to understand the claim that, at $t_{1}$, a normal, conscious human agent, $S$, can $A$ at $t_{2}$ is as the assertion that, at $t_{1}, S$ has at least what we dub 'the bare actional possibility' of $A$-ing at $t_{2} . S$ has at least this possibility if and only if, at $t_{l}$, the combination of the past and the laws of logic is consistent with $S$ 's $A$-ing at $t_{2}$. In characterising bare actional possibility-that is, ability in that sense, what we have called 'metaphysical ability'-we do not appeal to the laws of nature in the agent's world, for, assuming Humeanism, how the laws pan out is contingent on what agents do, which depends in turn on what it is possible for them to do, in a broadly logical sense of 'possible'.

Although, consistently with the assumption of Humeanism, the laws of nature in an agent's world are no bar to bare actional possibility, they may preclude some more robust agential abilities. One such ability concerns relatively basic overt actions of a normal, conscious human agent. Treating deciding to $A$ as the mental action of forming an intention to $A$, and understanding its being the case that $S$ can decide to $A$ as a matter of $S$ 's having at least the bare actional possibility of deciding to $A$, we offer the following: At $t$, a normal, conscious human agent $S$ is $b$-able to perform a 
relatively basic overt action, $A$, straightaway if and only if, at $t, S$ can decide to $A$ straightaway, and, were $S$ to decide to $A$ straightaway, then $S$ would $A$ straightaway. We assume a Lewis-style analysis of counterfactuals, according to which the laws of $S$ 's world are held fixed as far as possible for the purposes of testing the counterfactual. ( $b$-ability is a bit stronger than a similar notion of ability that leaves open failed attempts to perform relatively basic overt actions, and it is weaker than a similar notion that requires more than the bare actional possibility of deciding to $A$.)

Fred, seated at his breakfast table, is $b$-able to raise his arm then, since, if he were to decide to raise it, he would do so. At the closest world where he decides to do so-a world that, relative to the actual world, contains a small 'miracle'-he does indeed raise his arm. However, Fred is not $b$-able to move his arm faster than the speed of light, for even if he were (perversely) to decide to do so, he would not succeed. At the closest world where he decides to move his arm that fast, he fails to do so. For a world where he decides to do it but fails contains just the one, small miracle just prior to the time of decision, but a world where he decides to do it and succeeds contains not just that one small miracle but also a second miracle-the one that enables him actually to move his arm faster than light.

Thus, according to a Humean conception of laws, Fred has the bare actional possibility both of deciding to raise his arm and of deciding to move it faster than light. He also has the bare actional possibility both of raising his arm and of moving it faster than light. But, whereas he is $b$-able to raise his arm, he is not $b$-able to move it faster than light. He is able to move his arm that fast in the bare actional possibility sense, but not in the $b$-ability sense. Agents are able to decide to $A$ when they do not in fact decide to $A$, in the sense that they possess the bare actional possibility of deciding to $A$. Whether or not agents are thereby able, in some more robust sense, to 
$A$ (where $A$ is a relatively basic overt action) depends on whether, were they to decide to $A$, they would $A$. Fred is $b$-able to raise his arm (assuming that were he to decide to do so, he would do so), but he is not $b$-able to move it faster than light.

The concept of $b$-ability may be more restrictive than we have suggested so far. $S$ has the bare actional possibility at $t_{1}$ of deciding at $t_{1}$ to $A$ at $t_{2}$ if and only if, at $t_{1}$, the combination of the past and the laws of logic is consistent with $S$ 's so deciding at $t_{1}$. Suppose the laws of logic are understood broadly, to include all conceptually necessary truths, including any such truths about deciding. Conceptual work on deciding may show that $b$-ability is less inclusive than one might have thought. Consider, for example, the following theses:

T1. As a matter of conceptual necessity, an agent's being convinced at $t_{1}$ that she cannot $A$ at $t_{2}$ renders her unable at $t_{1}$ to decide at $t_{1}$ to $A$ at $t_{2}{ }^{9}$

T2. As a matter of conceptual necessity, an agent's being convinced at $t_{1}$ that there is absolutely nothing to be said for her $A$-ing at $t_{2}$ and absolutely nothing to be said for her deciding at $t_{1}$ to $A$ at $t_{2}$ renders her unable at $t_{1}$ to decide at $t_{1}$ to $A$ at $t_{2}{ }^{10}$

These theses, if true, would constrain $b$-ability to $A$ by constraining the ability to decide to $A$.

Humeans, then, can distinguish bare actional possibility from stronger kinds of agential ability. They can, in a principled way, identify a sense of 'able' in which Fred, who ate toast, was able to eat cake that is not a sense in which Fred, who did not raise his arm faster than the speed of light, was able to do that. The worry that

\footnotetext{
${ }^{9}$ Incidentally, an agent may or may not believe that she can do such things as move her hand faster than the speed of light.
} 
Humeanism about laws is false because Humeans cannot make such distinctions-or cannot accommodate the commonsense idea that there is a legitimate sense of 'able' in which we are not able to run faster than the speed of light but are able to eat cake for breakfast (even though, in fact, we eat toast instead)-is unfounded. The preceding is just one illustration of this. Whether Humeans can identify a kind of ability and a set of conditions such that agents with that kind of ability to have acted otherwise who satisfy those conditions have acted freely is a question we leave open, just as we leave open the question whether libertarians can identify such a kind of ability and such a set of conditions. The nature of these projects becomes clearer as we proceed, but we point out now that dual $b$-ability, which is compatible with determinism on a Humean view of laws, may come closer to turning the trick than bare actional possibility does. In any case, it is no part of our purpose in this paper to offer a solution to the free will problem. Again, our aim is to situate Humean compatibilism in the free-will debate.

We conclude this section with a comment on necessitarian and Humean compatibilisms. In a paper setting out a challenge for incompatibilist opponents of a Humean brand of compatibilism, Kadri Vihvelin writes:

A compatibilist can and should claim that there are deterministic worlds at which agents are free to do otherwise in just the sense that the incompatibilist denies-nothing prevents them from exercising their unconditional and categorical ability to do other than what they in fact do. Notwithstanding recent compatibilist attempts to argue otherwise, this is a minimal requirement of any kind of free will worth wanting. (1990, p. 371)

${ }^{10}$ Arguably, in some scenarios in which there is a payoff specifically for an agent's deciding to $A$ that 
One way to understand a necessary condition of an agent's having the dual ability to which Vihvelin alludes here is as follows: An agent $S$ who $A$-ed at $t$ in world $W$ (and who therefore was able at $t$ to $A$ then) was able at $t$ to do otherwise at $t$ only if in a possible world with the same past as $W$ relative to $t, S$ (or a counterpart) does otherwise at $t$. A compatibilist who is a necessitarian about laws of nature should reject the claim that free action and moral responsibility depend on dual ability of this kind. On a necessitarian view of laws of nature, determinism is incompatible with this ability. For on this view of laws, part of what we do in holding $W$ 's past fixed is to hold its laws fixed - the necessitation relations that are $W$ 's laws are part of its past. Holding all this fixed is logically sufficient for $S$ 's $A$-ing at $t$.

A necessitarian compatibilist may either accept or reject the necessary condition for dual ability that we stated. Semicompatibilism is the obvious choice for those who accept that condition. This, again, is the view that compatibilism is true even if, as incompatibilists claim, determinism is incompatible with dual ability. Necessitarian compatibilists who reject the condition at issue should try to construct an account of dual ability that is compatible with the combination of determinism and necessitarianism about laws of nature and identifies something such that, if all the other conditions for freedom and moral responsibility with respect to her A-ing are satisfied by an agent, adding this ability to the mix renders the action free and one for which the agent is morally responsible. We wish such compatibilists luck in this endeavor.

\section{Humean compatibilism, libertarianism, and luck}

does not depend on her $A$-ing (as may be the case in Kavka's toxin puzzle [Kavka 1983]), an agent 
It is often thought that if compatibilism were shown to be true, little more would be required for a strong case that at least some human beings sometimes decide freely and freely execute those decisions-that they exercise free will. Relatively mundane things that can (at least arguably) preclude freedom include psychological compulsions, hypnosis, brainwashing, madness, systematic deception, some threats, and the like. These things are mundane relative to the fundamental nature of the universe. Libertarians (and other incompatibilists) maintain that if a world is deterministic, its agents lack free will no matter what else is true of them. Moreover, indeterminism is not itself sufficient for freedom, of course. Setting aside Cartesian dualism, libertarians want the brain to operate indeterministically-and not just in any old way, but in a way that supports freely made decisions and freely performed overt actions. Libertarians, then, seemingly are considerably more demanding about free will than compatibilists are and, accordingly, bear a significantly heavier burden than compatibilist believers in free will do in defending their beliefs in freedom. (A compatibilist need not believe in free will: to assert that free will is compatible with determinism is not yet to assert that anyone has free will.)

Compatibilists who take necessitarianism about laws for granted naturally suppose that when mature, rational human agents who are not constrained by problems of the sort mentioned in the preceding paragraph choose among apparent options, they typically choose freely. Free choice, for such compatibilists, is not a metaphysically deep phenomenon, as it is for libertarians. One may expect that all compatibilists-Humean and non-Humean alike--would fall into the same boat regarding the relative ease with which freedom is secured on the assumption that compatibilism is true. However, the dual ability that a Humean conception of laws 
provides seemingly makes shipmates of Humean compatibilists and libertarians on this issue. Although Humeans do not regard laws of nature as metaphysically deep, the 'openness' provided by Humeanism about laws generates an apparent obstacle to freedom that standard compatibilism does not encounter, an obstacle much like one featured in a familiar criticism of libertarianism. We conclude with an explanation of these points.

Libertarians face a problem about luck. The sphere of luck (good luck or bad) for an agent may be roughly identified as the sphere of things having the following two features: the agent lacks complete control over them; even so, they affect the agent's life. Luck, in this sense, is found not only in indeterministic worlds but also in deterministic worlds. Events that occurred long before we were born affect us, whether our world is deterministic or indeterministic, and we plainly have no control over the occurrence of such events. Libertarians and other incompatibilists appeal to deterministic luck in attacking compatibilism (witness the consequence argument), and compatibilists appeal to indeterministic luck in attacking libertarianism.

A standard libertarian claim is that, at least in all basic cases of free choice or decision, the agent 'might choose either way, all past circumstances remaining the same up to the moment of choice' (Kane 1996, p. 127; our italics). ${ }^{11}$ Some philosophers have argued that this requirement on freedom makes it a matter of luck that the agent chooses as he does rather than otherwise, and that such luck stands in the way of moral responsibility and the kind of freedom that such responsibility requires (see e.g. Strawson 1994 and Waller 1988).

\footnotetext{
${ }^{11}$ Kane takes this back later in the book (p. 172). For criticism of his modified view see Mele 1999a and Haji 1999. Kane replies in 1999a and 1999b.
} 
An illustration of the alleged problem is in order. ${ }^{12}$ Consider the following from van Inwagen, a libertarian:

To say that it was not determined that [a certain petty thief] should refrain from stealing is to say this: there is a possible world that (a) is exactly like the actual world in every detail up to the moment at which the thief refrained from stealing, and (b) is governed by the same laws of nature as the actual world, and (c) is such that, in it, the thief robbed the poor-box. (1983, p. 136)

To help his readers picture this, van Inwagen imagines that 'God has thousands of times caused the world to revert to precisely its state at the moment just before the thief decided not to steal' and that 'on about half these occasions' the thief refrained from robbing the poor-box (p. 141).

Van Inwagen suggests that in the actual world the thief's 'refraining from robbing the poor-box $(R)$ was caused but not necessitated by' a certain desire/belief pair (pp. 140-41). ' $R$ was caused by' this desire/belief pair $(D B)$, and ' $D B$ did not have to cause $R$; it just did' (p. 141). He also suggests that in those reruns in which the thief steals the money, his stealing was caused by another desire/belief pair (p. 141). Supposing that this is so, one worries that what the thief does is a matter of luck. One worries that it is just a matter of luck that $D B$ causes a refraining rather than the other desire/belief pair causes a stealing. If the thief had a tiny randomiser in his head-perhaps one that is 'a natural part' of his brain-that gives each of two competing sets of reasons an initial 0.5 chance of prevailing in his situation and then randomly issues in the prevailing of one set of reasons, the divine reruns would show

\footnotetext{
${ }^{12}$ For fuller illustrations, see Mele 1995 and 1999b. Parts of the next paragraph derive from the latter.
} 
the distribution that van Inwagen imagines they do. ${ }^{13}$ (Picture the device as a tiny, genuinely random roulette wheel, half of whose slots are black and half red. The ball's landing on black represents the prevailing of the thief's reasons for refraining from stealing and its landing on red represents the other reasons' prevailing.) But in that case, if the thief is not morally responsible for what the device does, it is hard to see how he can be morally responsible (or deserve moral credit or blame) for refraining from stealing in the actual world, or for stealing in the reruns in which he steals. At least, it is hard to see how his moral responsibility for refraining or for stealing, and for the corresponding decisions, can extend beyond his moral responsibility for his having the reasons he has at the time. And if his responsibility for having those reasons were to derive from earlier undetermined actions of his (including decidings) in which a randomiser of the kind described plays a central role, the same problem would arise at the pertinent earlier times. Parallel points may be made about freedom-level control over the action-producing process. ${ }^{14}$

At the very least, one wants a better story about how beliefs and desires result in actions, including acts of deciding. One wants a story that would reveal, or at least help us understand, why it is not just a matter of luck that in the actual world $S \operatorname{does} A$ whereas in a possible world with the same past and laws of nature $S$ (or a counterpart) does $B$ instead. This is not the place to explore such stories. Our present concern is a similarity between libertarianism and a Humean compatibilist's belief in free will.

It is easy to see that a Humean compatibilist who believes that at least some human beings act freely faces a very similar worry about luck. According to van Inwagen, if an agent decided to $A$, its being the case that he could have done

\footnotetext{
${ }^{13}$ Van Inwagen discusses the significance of behavior's proceeding from a 'natural part' of the brain on pp. 134-42. On this, see Mele 1995, pp. 197-203.

${ }^{14}$ The objection advanced in this paragraph does not depend on the probabilities that van Inwagen mentions. On this, see Mele 1995, pp. 202-3.
} 
otherwise than decide to $A$ requires that his deciding to $A$ was not causally determined, which in turn requires that 'there is a possible world that (a) is exactly like the actual world in every detail up to the moment at which' the agent decided to $A$, 'and (b) is governed by the same laws of nature as the actual world, and (c) is such that, in it,' the agent does something other than decide to $A$. A Humean compatibilist accepts requirements (a) and (c) on its being the case that an agent could have done otherwise than decide to $A$, but not requirement (b) (see Vihvelin 1990). Requirement (b) is rejected for a reason that has already emerged in this paper. For a Humean compatibilist, its being the case that an agent could have done otherwise lies in its being the case that pertinent laws of nature are up to agents in the way we have explained. Continuing to frame the issue in terms of possible worlds, a Humean compatibilist holds that an agent, Barney, could have done otherwise than decide to steal his neighbour's cake if and only if 'there is a possible world that . . . is exactly like the actual world in every detail up to the moment at which' he decided to steal her cake, and, in it, he does something other than decide to steal it.

A worry about luck leaps out. What accounts for its being the case that although, in the actual world, Barney decides at $t$ to steal the cake, in another 'world that ... is exactly like the actual world in every detail' until $t$, Barney decides at $t$ to go bowling instead? Apparently, there is nothing about the powers, capacities, states of mind, moral character, practical reasoning and the like of Barney the cake stealer and Barney the bowler that explains the difference in decision, given that the two worlds are exactly the same until $t$. So the difference seems to be a matter of luck. A Humean compatibilist may attempt to account for the difference in decision by appealing to a difference in laws; but if the pertinent laws themselves hinge on Barney's decisions, this smacks of unacceptable bootstrapping. 
We have no desire to argue that Humean compatibilist believers in free will cannot answer worries about luck, just as we have no desire to argue that libertarians cannot answer them. And we leave it open that what seems like unacceptable bootstrapping in fact is not. Our point is that the Humean believers and libertarians are pretty much in the same boat on this issue. In this, Humean and non-Humean compatibilists differ. The typical worry about luck voiced against the latter is a worry about what might be termed 'remote luck', the absence of control over conditions that were present long before we were born but affect us nonetheless. The worry for libertarians and Humean compatibilist believers in free will is a worry about 'present luck'-luck at the time of decision. At bottom, this shared worry derives from a 'could have done otherwise' requirement on freedom that entails a metaphysical openness that non-Humean compatibilists are unwilling to accept as necessary for freedom. If we are right, agents can satisfy a requirement of this kind in deterministic worlds, given a Humean conception of laws of nature. However, the supposition that a Humean conception of laws is correct does not make the existence of free will a piece of cake. $^{15}$

Centre for Philosophy HELEN BEEBEE Department of Government University of Manchester

Oxford Road

Manchester M13 9PL

UK helen.beebee@man.ac.uk

Department of Philosophy ALFRED MELE Florida State University Tallahassee, FL 32306-1500 USA almele@mailer.fsu.edu

\footnotetext{
${ }^{15}$ For comments on drafts of this paper, we are grateful to Randy Clarke, John Fischer, Barry Loewer, Michael McKenna, and Dave Robb. We also are grateful to audiences at the Australian National
} 


\section{REFERENCES}

Armstrong, D.M. 1983: What is a Law of Nature? Cambridge: Cambridge University Press.

Ayer, A. J. 1954: Philosophical Essays. New York: St. Martin's Press.

Beebee, Helen 2000: 'The Non-governing Conception of Laws of Nature'. Philosophy and Phenomenological Research, 56, pp. 571-594.

Fischer, John 1994: The Metaphysics of Free Will. Oxford: Blackwell.

Haji, Ishtiyaque 1999: 'Indeterminism and Frankfurt-type Examples'. Philosophical Explorations 2, pp. 42-58.

Kane, Robert 1996: The Significance of Free Will. New York: Oxford University Press.

1999a: ‘On Free Will, Responsibility, and Indeterminism'. Philosophical Explorations 2, pp. 105-121. 1999b: 'Responsibility, Luck, and Chance: Reflections on Free Will and Indeterminism'. Journal of Philosophy 96, pp. 217-240.

Kavka, Gregory 1983: 'The Toxin Puzzle'. Analysis 43: 33-36.

Lewis, David 1973: Counterfactuals. Cambridge, Mass.: Harvard University Press. 1986a: Philosophical Papers, vol. II. New York: Oxford University Press. 1986b: ‘Are we Free to Break the Laws?' in his 1986a, pp. 291-298. Originally published in Theoria (1981) 47, pp. 113-21.

Loewer, Barry 1996: 'Humean Supervenience'. Philosophical Topics 24, pp. 101127.

Mele, Alfred 1992: 'Intentions, Reasons, and Beliefs: Morals of the Toxin Puzzle', Philosophical Studies 68, pp. 171-194. 
1995: Autonomous Agents: From Self-Control to Autonomy. New York: Oxford University Press.

1999a: 'Kane, Luck, and the Significance of Free Will'. Philosophical

Explorations 2, pp. 96-104.

1999b: 'Ultimate Responsibility and Dumb Luck'. Social Philosophy \& Policy

16, pp. 274-93.

Mill, John Stuart 1875: A System of Logic. London: Longmans.

Moore, G. E. 1912: Ethics. Oxford: Oxford University Press.

Ramsey, F.P. 1978: 'Universals of Law and Fact' in his Foundations, ed. D.H.

Mellor. London: Routledge \& Kegan Paul, pp. 128-132.

Strawson, Galen 1994: 'The Impossibility of Moral Responsibility'. Philosophical

Studies 75, pp. 5-24.

Swartz, Norman 1985: The Concept of Physical Law. Cambridge: Cambridge University Press.

van Inwagen, Peter 1983: An Essay on Free Will. Oxford: Clarendon Press.

Vihvelin, Kadri 1990: 'Freedom, Necessity, and the Laws of Nature as Relations Between Universals'. Australasian Journal of Philosophy 68, pp. 371-381.

Waller, Bruce 1988: 'Free Will Gone Out of Control'. Behaviorism 16, pp. 149-167.

Ridge, and Michael Smith, and to two anonymous referees for this journal. 